\title{
O storytelling nos videoclipes ${ }^{1}$
}

Brenda Lopes Siqueira

Pontifícia Universidade Católica do Rio de Janeiro - PUC-Rio

Departamento de Comunicação Social - Bacharelado em Jornalismo

\section{RESUMO}

Este é um artigo no campo de estudos de Cinema, Fotografia e Audiovisual que tem como objetivo analisar como se dá o storytelling nos videoclipes. Através da narrativa clássica americana, da montagem cinematográfica e de videoclipes de diferentes gêneros musicais existe um conteúdo audiovisual que se difere de todos os outros: o videoclipe musical. Cada clipe e cada uma das histórias contadas propiciam união entre música, imagem e narrativa. O objeto de análise é o videoclipe de Alicia Keys, da canção You Don't Know My Name, e suas especificidades. Pressupõe-se que a força imagética e da narrativa é tão grande, que na maioria das vezes a imagem sobressai em relação ao som e à música, tornando a narrativa o verdadeiro foco de quem assiste ao videoclipe. Assim, o clipe torna a canção apenas como um pano de fundo para a história que está sendo contada.

\section{PALAVRAS-CHAVE}

Videoclipe; Música; Narrativa clássica; Montagem cinematográfica.

\section{Introdução}

O videoclipe é considerado um conteúdo audiovisual muito diverso. Da mesma forma, o cinema é uma arte que transcende formatos, minutos de duração, cores, sons e limitações. $O$ videoclipe é uma forma de fazer cinema com uma união muito potente com a música. A música se torna uma narração, roteiro, guia para as imagens, para a história e para a montagem. A manipulação das imagens, tanto a montagem quanto a colorização, o que é filmado, o que a câmera mostra e como ela se move, todos esses recursos podem criar uma profundidade na composição imagética. Há uma proximidade, então, do videoclipe com o cinema. A união de todos esses elementos constitui um produto muito rico, cheio de camadas e interpretações.

\footnotetext{
${ }^{1}$ Artigo derivado de monografia de graduação em Cinema, orientada pela professora Cristina Bravo e apresentada em julho de 2019.
} 
Deve-se voltar aos anos 1950 quando artistas começaram a fazer conteúdos audiovisuais para artistas da música. Havia toda uma produção que buscava realçar a imagem do artista/banda, e posteriormente, realçar o alcance e rentabilidade da música. O videoclipe transcende, nesse sentido, as próprias barreiras do cinema, que não fica fechado somente a ser ou não narrativo, mas também pode ser uma peça para o mercado publicitário, para vender tanto o artista/banda e a música.

Busca-se através do artigo pensar como os videoclipes de gêneros musicais diferentes apresentam uma estrutura parecida: a união da música e da narrativa clássica do cinema americano. Alguns clipes têm em sua estrutura a narrativa com a introdução dos personagens, um arco de personagem complexo, e uma história bem delineada. Os clipes dos artistas desenvolvem histórias complexas em apenas alguns minutos, conciliando nesse pouco tempo tanto a música, como publicidade e venda da imagem do cantor, junto com uma narrativa cheia de simbologia e rica em conceitos, revelando outras camadas para a música.

A montagem de um roteiro com uma história de início, meio e fim, a iluminação, a atuação, e a produção de arte, são ferramentas para construção de uma narrativa, fazendo com que o clipe produza uma história só sua. Então, ele se torna indústria fonográfica, tornando-se quase um curta cinematográfico, somente pelo peso imagético.

A história do videoclipe mostra que os clipes são conteúdo audiovisual único e diferente de todos os outros, e a linguagem cinematográfica e alguns meios de comunicação influenciam desde a montagem até as narrativas de cada videoclipe. O cinema tem diversas maneiras de contar uma história, e os meios de comunicação, cada um tem seu tempo, público e formato. Já o videoclipe passeia por todos esses campos.

Na primeira seção deste artigo, há um breve contexto histórico do videoclipe desde os anos 1960 , e como o seu sentido continua sendo flutuante e sem uma definição ou uma categoria que possa ser encaixado. Os gêneros musicais têm grande influência em como a imagem será fabricada, em qual será o nível de experimentação do produto final, se o artista será exaltado no clipe ou não e se a narrativa se constrói através da música ou simplesmente pela vontade do artista e do diretor. Na segunda seção, será explicada a narrativa clássica americana e suas reverberações no cinema, o poder da trilha sonora na construção de sentido para a imagem e finalmente, a montagem como principal ferramenta para construção de uma história, tanto no cinema, quanto nos videoclipes. Na terceira seção, será realizada uma análise de um videoclipe narrativo à luz da narrativa clássica e da montagem, e todas as camadas de narrativa que podem ser observadas através desse vídeo. 


\section{Os videoclipes}

O videoclipe ganhou força nos anos 1980 e continua sendo um produto diferente de todos os outros conteúdos audiovisuais porque permeia muitos campos da comunicação. Desde conteúdo publicitário para o cantor, para alguma marca até um curta de cinema. Além de serem assistidos desde em uma grande tela até em um indoor TV de um transporte público e uma tela de smartphone. São capazes de iniciar a carreira de algum cantor, na atualidade com a potencialidade da internet, o vídeo viral, dá muita notoriedade, tanto pela questão imagética, quanto pela narrativa, como por exemplo: Just Dance de Lady Gaga, Baby de Justin Bieber e Gangnam Style de Psy.

O nome videoclipe vem de clipping, recorte, clip, com a junção de fragmentos e de clipes um videoclipe é montado. Através dessa palavra temos a nocão de recorte, pinca ou grampo. A própria nomenclatura já nos apresenta uma característica: a idéia de velocidade, de estruturas enxutas e uma influência da edição e montagem. Os videoclipes têm diversas maneiras de serem realizados e com diferentes narrativas. Ao longo da história, desde os anos 1960, esse tipo de conteúdo mudou de conceito e ainda tem um sentido flutuante, não é um curta-cinematográfico, não é um filme publicitário, não é um documentário, mas pode ser tudo isso, apresentando um hibridismo na sua conceituação.

No início era um tipo de material promocional do artista/banda, para a popularização da música e venda da imagem do cantor. O videoclipe deixou de ser apenas um vídeo promocional para a indústria musical e passou a ser considerado uma obra audiovisual com características bastante expressivas, articulando uma identidade própria. Nele eram mostrados apenas os cantores e as bandas fazendo suas performances na frente da camera, aparecendo durante o vídeo inteiro. Hoje o videoclipe não tem somente essa única função, mas ele conta uma história muito própria, às vezes recriando sentidos dentro da própria canção e atravessando o que a letra quer dizer, colocando a música em segundo plano.

\section{Gêneros musicais e a construção do clipe}

Os videoclipes não se relacionam somente com um gênero musical. Eles têm um conteúdo audiovisual mercadológico e de grande alcance e aceitação. Diversos gêneros musicais produzem clipes das mais variadas formas, inclusive narrativos. Existem diversas maneiras de fazer um videoclipe, desde um minidocumentário mostrando o dia a dia do cantor/banda 
e um minidocumentário da turnê e da vida agitada de shows, assim como clipes narrativos com uma história sendo desenvolvida, clipes totalmente experimentais, sem existir necessariamente alguma coerência com a canção. A escolha de qual caminho seguir está nas mãos da gravadora, do cantor e do diretor, mas, podemos ver algumas tendências de acordo com o gênero musical.

Um exemplo é o clipe da música Cool de Gwen Stefani, cantora norte americana que ficou famosa através da banda de rock chamada No Doubt nos anos 1990. A partir dos anos 2000 Gwen seguiu carreira solo no Pop, e em 2003, lançou a música e o clipe Cool. A música não é uma de suas mais famosas em sua carreira, mas ganhou muita notoriedade através do videoclipe, atualmente com 117.801.991 visualizações² ${ }^{2}$ O gênero musical pop tem um apelo mercadológico maior do que os outros gêneros e a explicação está na própria origem do termo: pop vem de Popular. Cujas músicas são feitas com foco maior na performance e na grande acessibilidade de todos os ouvintes.

Já o R\&B, abreviação de Rhythm and Blues, tem como uma de suas características a união de estilos musicais como o jazz, blues, hip hop e soul music. Os principais nomes desse gênero musical são cantores reconhecidos como Whitney Houston, Aretha Franklin, Beyoncé, Stevie Wonder, Earth Wind and Fire, Usher, Marvin Gaye, Frank Ocean, Lauryn Hill, D'Angelo. Todos esses cantores são negros e desempenharam um papel insubstituível para a construção de uma identidade negra tanto nos Estados Unidos quanto mundialmente. Esse gênero musical tem uma função para além da música e de um gênero na indústria fonográfica. Ele apresenta uma união de temas, ritmos para a comunidade negra, principalmente afroamericana, com músicas onde os traços físicos dos negros são exaltados, de cunho social com críticas à sociedade americana e à postura racista do mundo, assim como temas universais como amor, coração partido, paz, festas e alegria.

Como a música é um produto em constante construção e os instrumentos são muito versáteis, é raro ver algum gênero musical que não tenha derivado ou não seja a união de outros ritmos. O Indie Folk é um ritmo que tem ganhado notoriedade ao longo dos anos, e surgiu mais recentemente nos anos 1990. Assim como o gênero musical Country, as músicas têm uma grande história sendo narrada, que falam de amor e da vida no campo, e o seu conteúdo audiovisual é ritmado, editado e pensado incorporando essas questões. Assim, como o R\&B, o indie folk também é a união de country, folk e do indie. Algumas bandas como The Lumineers, Beirut, Mumford and Sons são os maiores representantes desse estilo, com

\footnotetext{
${ }^{2}$ Número de visualizações checado no dia 15 de Agosto de 2019 em https://www.youtube.com/watch?v=TGwZ7MNtBFU
} 
músicas extremamente complexas e difíceis de tocar, com uma grande quantidade de instrumentos, bandas com quatro ou mais integrantes e temas universais em suas letras, mas o que está em evidência é o tema amor e a vida simples no campo.

The Lumineers é uma banda de indie rock que na maioria de seus projetos desenvolve um conteúdo audiovisual narrativo, seja um clipe isolado a clipes que se conectam e desenvolvem a história de um mesmo personagem, até mesmo um álbum inteiro só de músicas que contam uma história sobre alguém, e os clipes seguem esse caminho. Na música Sleep on the floor da banda, um homem diz várias coisas para a mulher que ama, na intenção de alertá-la a seguir seu coração e decidir fugir de sua rotina. Ele pede para que ela faça uma mala muito simples: traga sua escova de dente, sua blusa favorita e suas economias. A personagem principal o chama para uma vida com ele, longe da cidade onde estão, e ele deseja uma resposta para já, o quanto antes, para que ela decida escolher ele.

As escolhas estéticas estão diretamente relacionadas ao gênero musical, e isso se evidencia através dos clipes que serão analisados. Janotti Jr. (2005) diz que:

Torna-se necessário esclarecer então que, antes de ser um operador duro, que ignora as especificidades de cada materializacão do eixo paradigmático em manifestacão midiática, a abordagem dos generos é dinamica e suficiente para dar conta dos rótulos e de suas manifestacões particulares. Esses percursos minimizariam em parte a idéia de que os generos seriam pré-determinantes no processo de producão de sentido da cultura midiática. Assim, a configuracão de determinados tracos estilísticos de genero em um produto midiático define um processo de producão de sentido e, consequentemente, de comunicacão, que pressupõe regras formais e ritualizacões partilhadas por produtores e audiencia. (JANOTTI JR., 2005, p. 198)

Nos clipes de R\&B, como Burn do Usher, So Sick do Ne-yo, Rain on Me de Ashanti, é notável o uso da câmera lenta como uma ferramenta de montagem que traz dramaticidade para as canções, que em sua maioria são sobre amor, relacionamentos e críticas sociais. Já no pop, clipes como Radar de Britney Spears, Wildest Dreams de Taylor Swift, Girlfriend de Avril Lavigne são exemplos de como a imagem da cantora pop é ressaltada, evidenciada e sexualizada. No Pop, a montagem é muito dinâmica e enxuta, com muita inserção de imagens. O apelo e a atração da música pop são diferentes do R\&B, nos clipes de Pop existem cenas totalmente dedicadas à exaltação do cantor, como se fossem spots publicitários. Nos clipes de indie folk, como Cherry Wine de Hozier e Beloved de Mumford \& Sons, são clipes com uma imersão da narrativa em todos os aspectos, cor, roteiro, atuação. As bandas não são inseridas em momento algum, os integrantes não aparecem nos clipes a não ser que de 
fato eles desempenhem algum papel dentro da narrativa e também através da canção, que é uma trilha sonora para a história que está sendo contada.

\section{A narrativa: entendendo o storytelling}

A narrativa cinematográfica pode se construir a partir de alguns elementos fílmicos: a montagem, o próprio roteiro, os movimentos de câmera, a iluminação, figurino, a cor, o formato (aspect ratio), o desempenho dos atores e os efeitos na pós-produção. Também com o uso da perspectiva, ângulos, cenografia. Dentro de todos esses elementos fílmicos, o que inicia toda a trajetória de um filme é o seu roteiro, quando se pensa como a história será contada e como a narrativa irá se desenrolar. Primeiramente, uma explanação sobre a narrativa clássica americana.

A narrativa do cinema clássico é construída através da causalidade, onde ações e conseqüências guiam as histórias dos personagens. Para que essas relações de causa e efeito construam a narrativa é necessário que cada cena tenha um gatilho, com algo a ser definido para a cena seguinte, que é utilizado como ponto de partida para o desenvolvimento da história. Então, na próxima cena, é retomado o que não se resolveu na cena anterior, e a tentativa de resolução dá origem a novas linhas causais, que ficam como gatilho das cenas posteriores. Dessa forma, a linearidade da história, a partir das relações de causa e efeito, é mantida. Como se fosse uma eterna linha de acontecimentos gerados a partir de uma relação não tão simples de causa e efeito, que pode sustentar narrativas longas e pequenas.

A estrutura da narrativa clássica é chamada dessa forma pela maneira como a maioria dos filmes são realizados, principalmente em uma das maiores indústrias do cinema mundial, Hollywood, desde os primórdios do cinema. É a estrutura mais comum de se contar uma história e a narrativa clássica se apoia em um formato de três atos: o setup, o desenvolvimento e a resolução.

O primeiro ato é o setup. Ele se inicia com a introdução dos principais personagens da história, seus objetivos, seus obstáculos que muito provavelmente enfrentarão para atingir seus objetivos. O principal conflito da história é introduzido, assim como o maior vilão/ antagonista, que irá ficar no caminho do protagonista/herói e seus objetivos. O primeiro ato do filme na narrativa clássica é o gancho. Cria uma base introdutória, com algumas camadas que serão 
desenvolvidas depois e toda uma história que chama atenção da audiência e sugere um futuro desenvolvimento.

O segundo ato é o desenvolvimento. Nesse ato, complicações no roteiro e na história são adicionadas à narrativa. Um senso de urgência crescente é criado quando os principais personagens ficam face a face com seus obstáculos que estão no caminho em suas jornadas. O segundo ato costuma ocupar os dois quartos do filme e gera uma falsa solução para o conflito principal estabelecido no primeiro ato. Uma vez encontrada a falsa resolução, a ação no filme aponta inevitavelmente para um clímax necessário. Ao longo do segundo ato, relacionamentos de causa e efeito que impulsionam os personagens principais. As relações de causa e efeito envolvem ações que forçam uma reação da parte de algum personagem, levando a uma nova ação e reação, e assim por diante.

O terceiro ato é a resolução, o último segmento do filme. Os resultados do principal conflito da história chegam a um confronto dramático, o clímax da história. Isso é chamado de clímax. É o ponto em que as principais lutas são travadas e um eventual vencedor é determinado. Nos longas de Hollywood, o eventual vencedor é geralmente o herói. Após o clímax, o encerramento é introduzido na história, o que significa simplesmente que todos os principais conflitos, questões ou ideias da história foram resolvidos. O chamado "fim de Hollywood" é o tipo mais popular de fechamento na estrutura narrativa clássica. Filmes com esse tipo de conclusão geralmente se encerram com a sensação de que os protagonistas do filme vivem felizes para sempre.

\subsection{O papel da montagem}

A imagem constitui o elemento de base da linguagem cinematográfica. Ela é a matéria prima fílmica, simultaneamente, uma materialização de tudo o que foi desenhado pelos cineastas. A imagem reproduz o real, eventualmente, afeta os nossos sentidos e sentimentos, dá um ritmo ao filme e finalmente, toma uma significação ideológica e moral. Como define Eisenstein, a imagem nos conduz ao sentimento afetivo. $O$ que está enquadrado e o quadro fílmico, para Eisenstein, é uma célula de montagem, uma molécula e a nocão de conflito vai estar no centro e ao redor de sua articulacão. A relação da imagem e da montagem se dá dessa forma para Eisenstein:

[...] A montagem toma por base a imagem única, unificadora, determinada por suas partes componentes, desempenhando um papel decisivo no fazer cinematográfico e na criatividade. Não deve haver limites arbitrários à variedade dos meios expressivos que podem ser utilizados pelo cineasta. Todos os seus vários elementos: os elementos puramente plásticos, o elemento visual, o que indica o comportamento 
humano, que é o elemento dramático, e os e sons, todos são igualmente fundidas numa imagem única, unificadora, definitiva. (EISENSTEIN, 1990, p. 52)

Arlindo Machado no livro Pré e Pós Cinemas aborda como no cinema a montagem é a melhor ferramenta para a construção de sentido. A montagem é a responsável por estruturar e dar continuidade à história, uma montagem sem continuidade torna o filme sem nexo e sem narrativa. O cinema é uma arte audiovisual, ou seja, tanto o conteúdo sonoro, quanto o conteúdo visual são responsáveis por contar as histórias, principalmente através de como tudo é montado e essas escolhas têm um efeito na construção de sentido do filme. A disposição do que foi filmado através da edição faz com que o filme exista, e a edição em si já é um recorte do que entra ou não no produto final.

O efeito Kuleshov, criado através de experimentos do cineasta Lev Kuleshov, é um efeito criado a partir da montagem onde ocorre uma sucessão de planos que criam um sentido. Cada plano separado do outro não faz sentido algum, mas quando um sucede o outro, ali está o filme narrativo e ali a montagem se faz de forma eficaz. Esse efeito faz parte do cinema clássico e do cinema narrativo há anos. O exemplo utilizado por Eisenstein em seu livro $O$ Sentido do Filme fala de maneira clara como funciona o efeito Kuleshov:

[...] Dois pedaços de filme de qualquer tipo, colocados juntos, inevitavelmente criam um novo conceito, uma nova qualidade, que surge da justaposição. Estamos acostumados a fazer, quase que automaticamente, uma síntese dedutiva definida e óbvia, quando quaisquer objetos isolados são colocados à nossa frente lado a lado. Por exemplo, tomemos um túmulo, justaposto a uma mulher de luto chorando ao lado, e dificilmente alguém deixará de concluir que se trata de uma viúva. (Eisenstein, 1990:14)

\section{A montagem paralela}

A montagem paralela mostra dois eventos ocorrendo sucessivamente, em dois planos separados, até que no ápice do filme os dois se encontram, e o desenrolar dos acontecimentos acontece de forma paralela e os dois culminam no mesmo ponto. É uma ferramenta que acrescenta camadas à narrativa, outras perspectivas e dinamicidade na história.

Para o autor David Bordwell, no seu livro $A$ arte do cinema, esse tipo de montagem faz uso dessa ferramenta que "oferece, portanto, certa descontinuidade espacial, mas amarra a ação ao criar uma percepção de causa e efeito de simultaneidade temporal." (BORDWELL, 1979, p. 473). Tal simultaneidade temporal, mencionada por Bordwell, cria uma multiplicidade de eventos, que nos dá informações temporais, causais e espaciais sobre a história. 
Câmera lenta

A câmera lenta é outro recurso de montagem, em que a imagem tem o seu ritmo consideravelmente diminuído, e a quantidade de quadros por segundo é muito menor. A câmera lenta dramatiza a imagem, trazendo uma carga emocional. Toda vez que esse recurso é utilizado, as expressões dos atores são valorizadas e a temporalidade é afetada, criando tensões para além do que de fato a imagem mostra, aumentando a agonia no espectador. É muito utilizado para sugerir que o personagem está passando por algo que o tira de seu estado normal, como uma alucinação, embriaguez, e também serve de efeito de impacto nos filmes de ação, realçando atos heróicos.

\section{Storytelling nos videoclipes}

Busca-se nessa seção analisar - à luz dos conceitos anteriormente introduzidos - o videoclipe escolhido. O cinema, como descrito acima, tem uma linguagem própria que nos permite compreender os sentidos produzidos. Dessa forma, a narrativa clássica, explicada e comentada anteriormente, apresenta alguns recursos cinematográficos que compõem a linguagem cinematográfica. Iremos identificar os símbolos que contribuem para a producão e construcão do sentido que façam conexões claras com a narrativa clássica.

Nesta seção a análise será sobre o amor platônico de Alicia Keys em You don't know my name, do gênero R\&B. O vídeo tem como foco contar uma história de amor, com suas particularidades e com um desfecho. Conforme descrito anteriormente, a diferença dos gêneros musicais tem um efeito nas músicas escolhidas, desde o roteiro, a duração dos clipes, a fotografia, até mesmo às cores utilizadas.

\subsection{0 amor platônico}

You don't know my name é um clipe longo, de 6 minutos. A música é recheada de viradas e quebras, enriquecendo a narrativa de uma mulher perdidamente apaixonada, cheia de inseguranças, dúvidas, com um amor de início não correspondido. O cenário é um restaurante, um pequeno jukebox aparece com a música e o nome da cantora, e uma cliente do restaurante deposita algumas moedas para ouvir a música. 


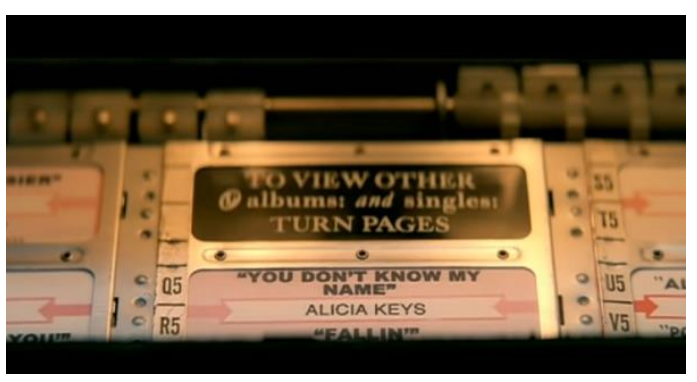

Figura 1

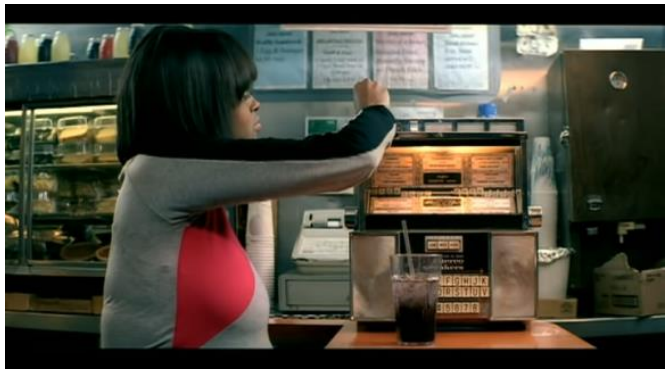

Figura 2

Alicia Keys vive uma garçonete de um restaurante bem no meio da agitada Nova York, ela trabalha em um restaurante movimentado, com grande circulação de todo tipo de gente e muitas demandas de trabalho. Nesta breve introdução não ouvimos a música, mas o som ambiente do restaurante, clientes conversando e sons da cozinha. Alicia entra apressada pelo restaurante e começa a se preparar para sua jornada quando uma de suas amigas garçonetes diz: "Seu homem chegou" (figura 3). Ela se vira (figura 4) e o olha, ele entra em câmera lenta e a música se inicia, exatamente quando ele chega.
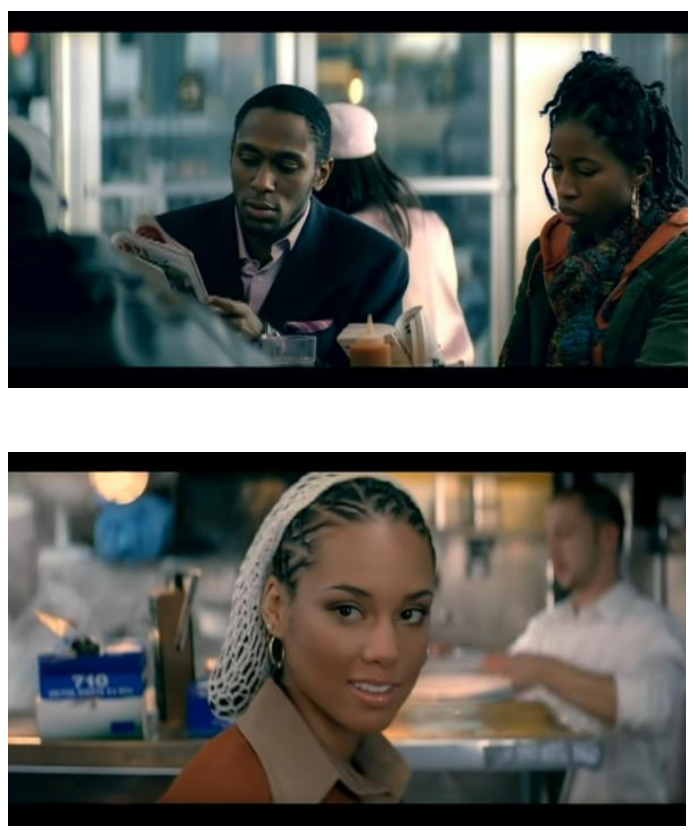

Figura 3

Figura 4 
Somente nessa primeira cena já podemos observar uma introdução do personagem, uma perspectiva muito clara de como é a correria da vida na cidade, e como o seu trabalho é intenso. Além da montagem mostrando a simultaneidade de eventos - pessoas no restaurante, Alicia se preparando, apressada e então, a chegada em câmera lenta do "seu homem". O uso da câmera lenta e a entrada da música são os dois recursos que introduzem e reforçam a mesma ideia: como Alicia está apaixonada.

Ainda no restaurante, o homem é atendido muito prontamente por uma garçonete - Alicia com um sorriso de orelha a orelha. Ele pede o lanche com "chocolate especial" e ela nem sequer anota o seu pedido, já sabe de cabeça, e capricha para que ao contrário dos outros chocolates especiais que são feitos com água para diluir o café, truque de seu chefe, ela põe creme para que ele sinta o real sabor do chocolate especial. A música que toca no jukebox e é a música do clipe segue como plano de fundo, como se estivesse sendo ouvida por todos com o pequeno jukebox, com os versos dizendo: "Oh baby / Desde o primeiro dia que te vi / Há algo especial em você / Eu preciso realmente lhe agradecer / Porque nem todos os caras valem meu tempo".

Nessa cena de apenas alguns segundos, o espectador desconfia se o amor de Alicia é conhecido pelo homem ou seria um amor platônico. Será que aquele amor é construído somente pela frequência que Alicia encontra e atende o homem? Eles se conhecem para além do restaurante? Fica claro quando ela se vira para levar seu pedido para a cozinha e ele a chama novamente e reforça que é um chocolate especial. Então entendemos, ela o nota de perto e de longe, mas ele não sabe. E então vem a música reforçando essa ideia: "Oh mas você não sabe o meu nome". A união da música com tudo o que estamos assistindo não é à toa, constantemente tudo o que ouvimos é reforçado pelo que vemos. Antes do homem ir embora, ele deposita seu cartão com seu contato numa caixa escrita: "ganhe um almoço de graça!" e sai.

A noite chega, a lanchonete fecha as portas e há um corte. Agora o cenário é outro: uma festa cheia de cores, pessoas, casais dançando. Alicia chega à festa com uma amiga, com um look totalmente diferente daquele que vimos anteriormente. Ela se encosta no canto da sala e vê seu homem chegar na festa, novamente ele chega em câmera lenta.

Os dois estão sendo iluminados por cores diferentes, ela com uma luz verde e ele com uma luz amarela. Ele encosta na mesma parede que ela está, olha para ela que rapidamente vira o rosto. O foco da câmera troca de Alicia para ele, e dele para Alicia. Quando eles trocam sorrisos, os dois estão sendo iluminados pela mesma cor verde, e começa uma briga e ele 
corre para separar - todos iluminados por uma cor vermelha. Nessa parte a luz é um elemento que recheia a cena, e traz significados.

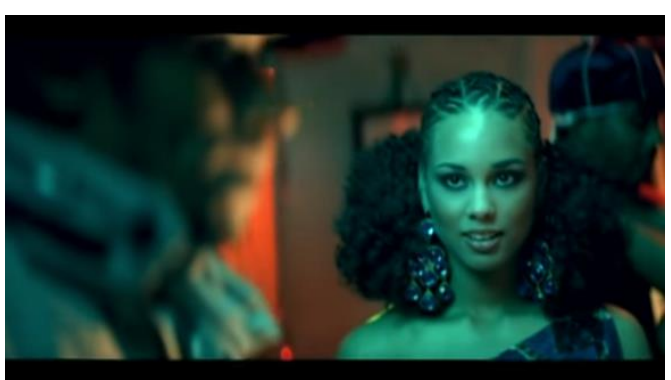

Figura 5

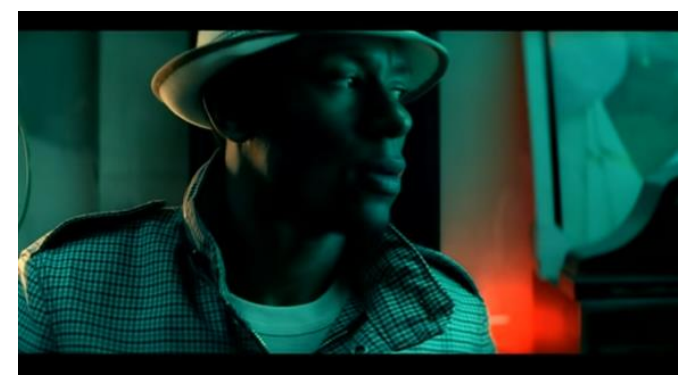

Figura 6



Figura 7

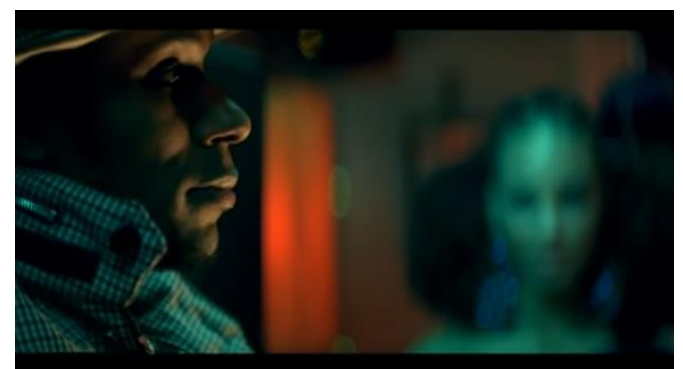

Figura 8

Com o final da festa, Alicia anda pela cidade até chegar a uma loja de pianos, onde toca sua música, totalmente entregue ao que a personagem sente naquele momento. Ainda nessa cena, a música diminui e desacelera, e ela diz: "Vou tomar coragem e vou ligar para esse homem". Enquanto ela fala, há uma montagem paralela, de volta ao momento em que ela vê e pega o cartão com o contato de sua paixão dentro da caixinha da promoção da lanchonete, e uma cena dela discando o número dele (figuras 9 e 10).

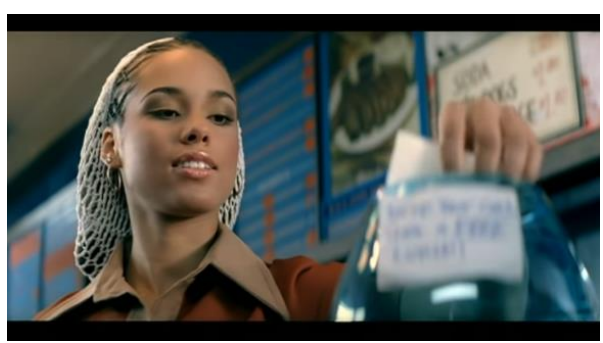

Figura 9

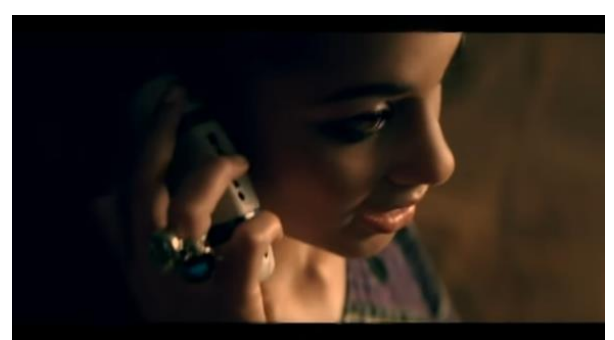

Figura 10

A conversa dessa parte em diante narra tudo o que vemos: ele, o restaurante, ela de garçonete, eles se beijando, ela com o celular e ele recebendo a ligação. Só conseguimos ouvir a voz de Alicia, seu jeito de articular a conversa sempre com cautela e ele continua em um enquadramento um pouco escuro, não ouvimos sua voz e nem suas expressões, mas vemos seu corpo reagindo e se movendo a cada frase que ela fala. 
Finalmente descobrimos o seu nome, ela liga e começa a falar: "Será que eu poderia falar com o Michael?". O diálogo segue, Alicia articula toda a conversa e não conseguimos ouvir suas respostas, mas tudo parece sair bem. Nesse momento no clipe vemos todo o tempo a montagem paralela e câmera lenta. Cenas intercaladas de Alicia no telefone, ao fundo o piano, Michael no telefone, Alicia beijando Michael, os dois juntos. A música segue ao fundo, só o instrumental, as vocalizações e harmonias da voz da cantora (figuras 11, 12, 13 e 14).

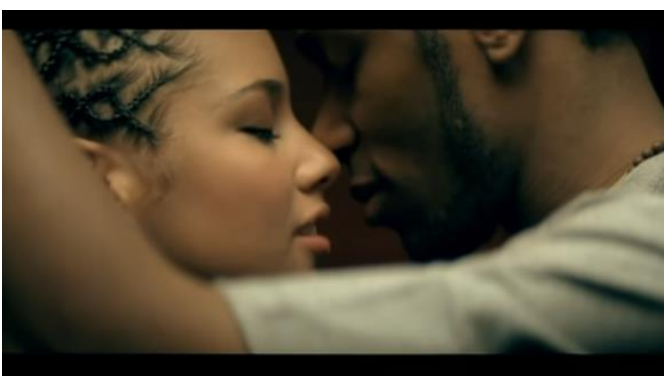

Figura 11

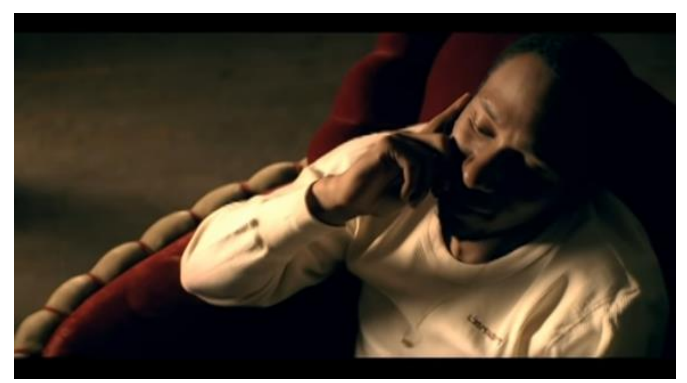

Figura 12

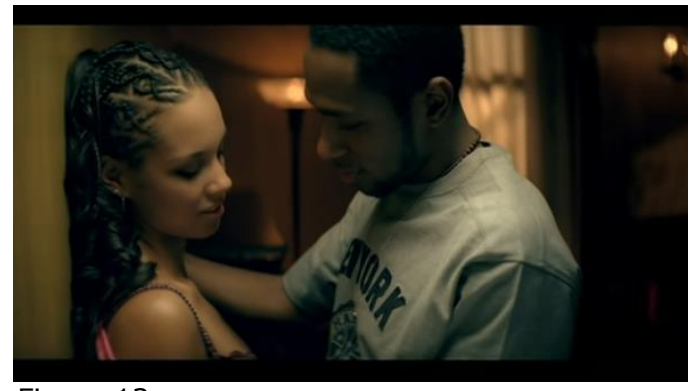

Figura 13

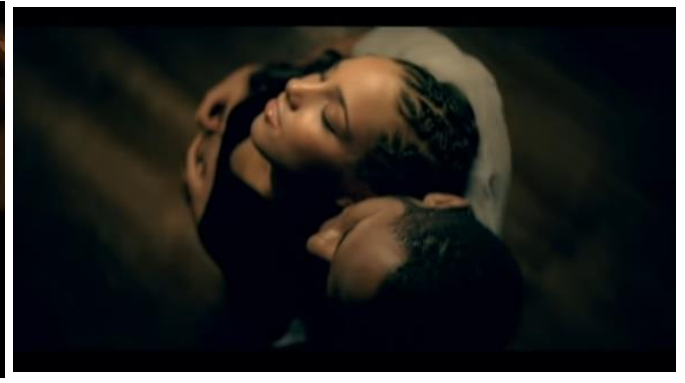

Figura 14

A sobreposição de imagens mostra que tudo o que Alicia mais desejava está acontecendo, a conversa com o homem dos seus sonhos. Enquanto isso, no seu imaginário, ela e Michael se beijam. A mistura de planos utilizando uma montagem paralela une o êxtase de ligar para o homem que ela se apaixonou, e a ansiedade para que tudo dê certo. O sentido é reforçado: paixão, desejo, flerte. Ainda nessa parte, na conversa ao telefone, Alicia diz: "eu sou bem diferente fora da roupa de trabalho", e vemos Michael em câmera lenta tirando a roupa de Alicia.

O instrumental da música não para de tocar ao fundo, enquanto eles conversam no telefone, ainda como um pano de fundo. Nessa cena, o trecho de Carol Vernallis descreve muito bem o que o clipe quer passar:

A edição reflete a estrutura musical e, ao mesmo tempo, transmite significado. Mas a edição pode executar funções ainda mais sofisticadas. Ao enfatizar determinados sons e imagens, um cineasta pode fornecer um caminho através da imagem, um caminho para o espectador. (VERNALLIS, 2004, p.51) 
O caminho para o espectador se dá nessa estrutura: a montagem paralela, o uso da trilha e a câmera lenta. Nessa parte do vídeo, esses três elementos guiam o espectador para celebrarem junto com Alicia: finalmente ela conseguiu, finalmente os dois se conheceram. $O$ nome da música é a estrofe que mais se repete em toda a canção, "Você não sabe o meu nome", mas agora o título da música não é mais a palavra final sobre a história: sim, ele sabe o nome dela.

De repente, vemos Michael entrar na lanchonete, há um retorno no tempo, de volta a primeira cena. Alicia se aproxima para atendê-lo e eles dois parecem distantes, ainda não se conhecem. Ela anota seu pedido e assim que ele come, levanta e sai. Ainda no expediente, ela observa Michael. Depois de depositar o seu cartão ele sai da lanchonete, ela está de longe e a última cena é Alicia acariciando a janela enquanto Michael vai embora. Então ela canta e repete o que a música toca de fundo na loja: "Será que um dia você vai saber?". Novamente, a música reforça o sentido, Michael continua um estranho e ela ainda vive em um campo de fantasias e de amor platônico.

A divisão do videoclipe, pensando na narrativa clássica, acontece no primeiro ato do vídeo, exatamente no momento em que Michael coloca seu cartão dentro da caixa de sorteio. $O$ segundo ato é o momento em que Alicia liga para ele, e eles conversam durante um tempo e marcam seu primeiro encontro. O terceiro ato, que é a conclusão, quando Alicia olha pela janela e vê Michael passar, e então o espectador percebe que ela nunca realizou a ligação.

Então, percebemos que o fato de não ouvir a voz de Michael, só as falas de Alicia, quer dizer que não houve em momento algum essa conversa. O espectador só se dá conta nos últimos segundos que tudo não passou de um sonho na mente de Alicia, e um dos principais recursos é a música ditando o que Alicia pensa, enquanto ela olha para Michael através da janela a música diz: E será que um dia você vai saber o meu nome?

\section{Considerações finais}

Desde o seu início, ainda nos anos 1950, os videoclipes sempre tiveram um espaço muito próprio na indústria fonográfica, se tornando assim, parte inseparável da indústria musical. Com a necessidade de acompanhar avanços tecnológicos causados pelo surgimento da televisão, cantores e bandas começaram a criar conteúdo audiovisual de suas canções, a pedido de suas gravadoras e produtoras. Os clipes, dessa forma, rapidamente se 
popularizaram, e se mostraram uma ferramenta atraente para o público, consolidando esse novo formato audiovisual.

As gravações dos videoclipes começaram a ser realizadas com performances ao vivo de bandas e cantores, como por exemplo, Elvis Presley, The Beatles e Queen. No entanto, ao longo das décadas, esse formato mudou e foram incorporadas novas ferramentas na realização de um clipe, desde performances ao vivo, spots publicitários, clipes experimentais com imagens desconexas e longe do mainstream e videoclipes narrativos. Em relação ao último formato, o videoclipe narrativo evoca uma união entre narrativa, música e imagem, que se difere dos outros porque tem o objetivo de envolver o espectador na história que está sendo contada, além de lembrar os musicais de Hollywood que sempre evocaram essa união entre música, imagem e narrativa.

Diante disso, esse artigo tem como justificativa trazer a um tema atual e pouco trabalhado no meio acadêmico tradicional da Comunicação Social, principalmente no contexto brasileiro. Assim, este trabalho pode ajudar em uma melhor compreensão da narrativa clássica americana, da montagem cinematográfica e como isso é arranjado e articulado nos videoclipes narrativos. Pode-se dizer também que o conteúdo audiovisual de um videoclipe, seus formatos e definições são bem fluidas, o que gera um campo de pesquisa muito rico e múltiplo, mas que é negligenciado cientificamente visto pela escassez de projetos acadêmicos sobre o tema. Portanto, esta pesquisa é relevante já que os videoclipes fazem parte de vários campos da sociedade passando pela publicidade, cinema, música, economia e cultura.

O propósito foi de analisar como se dá o storytelling nos videoclipes. Porém, devido a grande diversidade de conteúdo audiovisual de clipes, o recorte foi o videoclipe narrativo, focando em uma análise mais destrinchada do clipe You Don't Know My Name.

Nota-se que os gêneros musicais têm um efeito e uma clara influência sobre cada um dos videoclipes. Cada cantor e banda realizam o conteúdo audiovisual para suas canções de acordo com o gênero musical. Dependendo do gênero, o clipe muda todo o seu conceito, desde o roteiro até a montagem. Assim como a montagem, que é a principal ferramenta para a conceituação do videoclipe analisado. As camadas narrativas que são adicionadas enriquecem a história, além de trazer outros elementos para um vídeo de pouquíssima duração.

O objetivo geral foi analisar o uso da narrativa clássica americana e da montagem cinematográfica na conceituação dos clipes. O trabalho alcançou seu objetivo ao evidenciar que o uso da música, da narrativa clássica com uma estrutura de início, meio e fim, ou até 
mesmo de divisão em três atos - introdução, clímax, resolução -, juntamente com a montagem, seja paralela ou câmera lenta, contribuem para a construção de uma história/narrativa. O videoclipe escolhido se enquadra e utiliza tanto a montagem quanto a narrativa clássica americana, utilizando-se de uma linguagem cinematográfica (colorização, edição, roteiro, atuação).

Nos videoclipes narrativos, cada história contada é muito singular, e nota-se uma preponderância da imagem em relação à música no videoclipe analisado. A música de fato ocupou um lugar de segundo plano e tudo o que pudemos acompanhar foi a vida dos personagens, suas decepções e seus finais tristes. O clipe ganhou uma autonomia. Por mais que o vídeo desenvolva uma autonomia, não é uma obra sozinha. Nos videoclipes narrativos se desenrolam histórias que o espectador deseja ver e conhecer mais, porém ela está refém da música. Desde a primeira, até a última nota, podemos conhecer esses personagens, depois disso é só especulação e achismo. De acordo com Carol Vernallis:

A música recua para o segundo plano, como uma trilha sonora. As imagens de videoclipes ganham com a retenção de informações, confrontando o espectador com representações ambíguas ou pouco claras. Se há uma história, ela existe apenas na relação dinâmica entre a música e a imagem enquanto se desdobram no tempo. (VERNALLIS, 2004, p. 17)

Os estudos e análises dos videoclipes não devem se limitar ou se encerrar apenas nas limitações deste projeto. O próprio conceito do videoclipe é um recorte de vários e diferentes elementos e este tema passeia os mais diversos campos de estudo. Devido aos recortes que fiz ainda restam questões que deveriam ser aprofundadas, pesquisadas e analisadas como a receptividade do público de diferentes clipes, quais as tendências dos vídeos mais famosos do mundo que rapidamente "viralizam", como o videoclipe alavanca a imagem do cantor; são algumas questões que podem se desdobrar em outros estudos.

\section{Referências bibliográficas}

BORDWELL, David. A arte do cinema. São Paulo: Editora Unicamp, 2013. BORDWELL, David. Narration in the fiction film. Great Britain: Methuen \& Co., 1985. CARVALHO, Claudiane de Oliveira. Narratividade em videoclipe: a articulação entre música e imagem. V Encontro dos Núcleos de Pesquisa. Rio de Janeiro: XXVIII Intercom, 2005. 
COELHO, Lílian Reichert. As relações entre canção, imagem e narrativa nos

videoclipes. Belo Horizonte: XXVI Intercom, 2003.

DIAS, Márcia Tosta. Os donos da voz: indústria fonografica brasileira e mundializacão da cultura. São Paulo: Boitempo Editorial, 2000.

EISENSTEIN, Sergei. O sentido do filme. Rio de Janeiro: Zahar, 1990.

FARO, Paula. Cinema, vídeo e videoclipe: relações e narrativas híbridas. Rumores, v. 4, n. 8, 6 dez. 2010.

JANOTTI Jr., Jeder. Gêneros musicais, performance, afeto e ritmo: uma proposta de análise midiática da musica popular massiva. Trabalho apresentado no Intercom 2004. (mimeo).

JANOTTI Jr., Jeder e SOARES, Thiago. O videoclipe como extensão da canção:

apontamentos para análise. Revista Galáxia, n. 15, p. 91-108, 2008.

KEYS, Alicia. You don't know my name, publicado em 12 de Junho de 2011. Visitado em 05 de Maio de 2019 https://www.youtube.com/watch?v=_ST6ZRbhGiA.

MACHADO, Arlindo. Pré-cinemas \& pós-cinemas. 6a Ed. Papirus, 2011.

MOURA, Edgar. 50 anos, luz, camera e acão. São Paulo: Senac, 1999.

MUNDY, John. Popular music on screen: from Hollywood musical to music video.

Manchester: Manchester University Press, 1999.

OLIVEIRA, Robespierre e COLOMBO, Angélica Antonechen. Cinema e linguagem: as

transformações perceptivas e cognitivas. Discursos fotográficos, Londrina, v. 10, n. 16, p. 13-34, jan-jun./2014.

SOARES, Thiago. Videoclipe: o elogio da desarmonia. Recife: Livro Rápido, 2004.

STEFANI, Gwen. Cool, publicado em 5 de Outubro de 2009. Site visitado em 12 de Maio de 2019. https://www. youtube.com/watch?v=TGwZ7MNtBFU.

LUMINEERS, The. Sleep on the floor, publicado em 17 de Novembro de 2016. Site visitado em 17 de Maio de 2019. https://www.youtube.com/watch?v=v4pi1LxuDHc.

VERNALLIS, Carol. Experiencing music video: aesthetics and cultural context. New York: Columbia University Press, 2004. 